\title{
"COVID toes" as an exceptional indicator of asymptomatic COVID-19 contracted during a forced lockdown or before a quarantine
}

\section{Lorenzo Martini ${ }^{1,2}$, Piotr Brzeziński ${ }^{3}$}

${ }^{1}$ University of Siena, Department of Pharmaceutical Biotechnologies, Via A. Moro 2, 53100 Siena, Italy, ${ }^{2}$ C.R.I.S.M.A. Inter University Centre for Researched Advanced Medical Systems, ${ }^{3}$ Department of Physiotherapy and Medical Emergency, Faculty of Health Sciences, Pomeranian Academy, Slupsk, Poland

Corresponding author: Piotr Brzezinski, MD PhD, E-mail: brzezoo77@yahoo.com

Sir,

The coronavirus disease 2019 (COVID-19) pandemic caused by severe acute respiratory syndrome coronavirus 2 affects primarily the epithelium of the airways. With the increasing involvement of dermatologists in the management of the COVID-19 crisis, cutaneous symptoms have attracted their increasing attention. Cutaneous (skin) symptoms associated with COVID-19 in patients of all ages can be diagnosed and treated as well. Such disorders are caused by the direct action of SARS-CoV-2 on body tissues and the complement and coagulation systems, resulting in nonspecific eruptions of systemic viral infections. Knowing the cutaneous manifestations of COVID-19 may help in early diagnosis, triage of patients, and risk stratification [1].

Early studies from Central China reported low frequencies of skin disease in COVID-19 patients. Among the 1099 confirmed Wuhan cases studied, only $0.2 \%$ displayed cutaneous symptoms. With the closer involvement of dermatologists in the battle against the coronavirus pandemic, the interest in the cutaneous symptoms of SARS-CoV-2 infection has been increasing.

The first report from Northern Italy, which studied 88 COVID-19 patients, observed cutaneous symptoms in $20.4 \%$ of patients who developed cutaneous signs at the onset. Unfortunately, neither images nor histology were available.
Moreover, a recent letter from Thailand observes that almost all COVID-19 patients have all cutaneous signs.

There have been no cutaneous signs reported in patients living on the Tibetan Plateau, where the course of the disease has generally been mild. This means that temperature does not affect the incidence of the virus, contrary to the speculations often indulged in Italy that link high summer temperatures with decreasing risk of COVID-19 transmission, even in spite of no relevant scientific literature [2].

It is difficult to determine the actual reasons behind these findings. One explanation might be the involvement of dermatologists in triage, which results in a higher rate of skin diseases diagnosed. Another explanation might be that of the place of medical treatment: patients with severe diseases in intensive care units (ICUs) are likely to receive more attention for all possible clinical diagnoses compared to those with mild diseases and under outpatient care.

An important initiative in gaining useful symptomatic data has recently been undertaken by the American Academy of Dermatology (AAD) COVID-19 Task Force, which has launched an online COVID-19 dermatology registry to document the various cutaneous manifestations of COVID-19.

Chilblain-like edematous and erythematous eruptions have been observed in milder cases of COVID-19 and, in particular, in youngsters and young adults; they

\footnotetext{
How to cite this article: Martini L, Brzeziński P. "COVID toes" as an exceptional indicator of asymptomatic COVID-19 contracted during a forced lockdown or before a quarantine. Our Dermatol Online. 2020;11(Supp. 2):21-23.

Submission: 04.07.2020; Acceptance: 22.08.2020

DOI: $10.7241 /$ ourd.20202S2.8
} 
disappear after the infection without leaving scars. Chilblain-like eruptions are mostly asymmetrically distributed. Among more than 300 Spanish COVID-19 patients, almost $19 \%$ showed pseudo-chilblains. They may be associated with itch and pain and, on average, disappear after 2 weeks. A group of French dermatologists collected more than 290 cases of cutaneous manifestations. The most common was chilblain-like eruption (146 cases). Most of the contributors were dermatologists engaged in private practice with milder cases of COVID-19. Chilblainlike lesions in pediatric dermatological outpatients (with the mean age of 14 years) have been noted in 25 Spanish children. None of these children had the typical symptoms of COVID-19. Two-thirds were males, and the lesions were often asymptomatic. Mild pain (22\%) and itch $(11 \%)$ were the associated symptoms. The lesions disappeared within 2 weeks without treatment. In Lombardy, 14 cases- 11 children (with the average age of 14 years) and 3 young adults (with the average age of 29 years) — with chilblain-like eruptions were reported, with slightly more females involved than males. The authors described erythemato-violaceous papules and macules - some with bullae-and digital swelling. Mild itch was reported in three cases. In a study from Northern Italy, 63 cases of chilblain-like acral eruption were analyzed clinically with no gender preference. The median age was 14 years. The toes and feet were more often affected than the fingers and hands. Erythematous edematous lesions were the predominant feature, while blistering was observed in about half of the cases. Pain or itch was reported in $27 \%$ of the cases; pain with itch in $20.6 \%$. In $25.4 \%$ of the cases, lesions were completely asymptomatic. The median time from the onset to clinical diagnosis was 10 days. COVID-19 was mild with pyrexia in less than $5 \%$. In a series of 6 patients with chilblain-like acral eruptions, young patients (15-44 years) were either asymptomatic or displayed only mild COVID-19 symptoms. A 91-year-old male patient was hospitalized but recovered after 3 weeks [1-3].

That said, we had the chance to interview and, thereafter, treat 11 patients attested to have entered in contact with COVID-19 in a period between the end of January and April 2020.

At $27^{\circ} \mathrm{C}$ in the springtime, they showed the "COVID toes" (pseudo-chilblains) characteristic to the colder seasons. Many of them confirmed to have entered in contact with the virus during the lockdown or in the period before the quarantine imposed by governmental rulings and directives. All of them were completely asymptomatic.

If these patients - and people in a similar conditionleft lockdown, they would, conceivably, infect considerable numbers of healthy people through social interaction, walking in parks and roads, shopping, and spending time at bars and pubs.

We are sure that so-called "COVID toes" might be an excellent indicator of asymptomatic patients who never underwent proper testing. We propose such physical examination for future outbreaks of mutated coronaviruses.

Signs in the feet and fingers last for several weeks after contact with the virus. Moreover, it is reported that $37 \%$ of infected Italians have preferred to cure their COVID-19 at home instead of contacting public health services, which are often thought not to be a valuable resource.

For 6 months, no university, center of excellence, or hospital in all of Italy has proposed an official, applicable, and prepositive method of containing the virus-only palliatives, altercations, and political and commercial vaudevilles.

As far as our study goes, we treated our 11 cases successfully using an ointment of cantharus tinctorial tincture, bisabolol, collagenase, and vitamin A until complete restitutio ad integrum of pseudo-chilblains was achieved.

Cantharus tincture is essential in promoting the secretion of interleukin 6, co-involved in the occurrence of viral proteins, but we would like to highlight its potential for detecting asymptomatic patients, who constitute the most dangerous way of coronavirus transmission.

\section{Consent}

Examination of the patient was conducted according to the Declaration of Helsinki.

The authors certify that they have obtained all appropriate patient consent forms. In the form the patient(s) has/have given his/her/ their consent for his/her/their images and other clinical information to be reported in the journal. The patients understand that their names and initials will not be published and due efforts will be made to conceal their identity, but anonymity cannot be guaranteed. 
www.odermatol.com

\section{REFERENCES}

1. Hedou M, Carsuzaa F, Chary E, Hainaut E, Cazenave-Roblot F, Masson Regnault M. Comment on "Cutaneous manifestations in COVID-19: a first perspective " by Recalcati S. Eur Acad Dermatol Venereol. 2020;10.1111/jdv.16519.

2. Yoshida Y, Tsukamoto M, Muraoka K, Yoshida S, Shiraki K. Antiviral activity of macrophage-activating Chinese mixed herb hot extract. Tradition Kampo Med. 2017;5:19-25.
3. Wollina U, Karadağ AS, Rowland-Payne C, Chiriac A, Lotti T. Cutaneous signs in COVID-19 patients: A review. Dermatol Ther. 2020;e13549.

Copyright by Lorenzo Martini, et al. This is an open access article distributed under the terms of the Creative Commons Attribution License, which permits unrestricted use, distribution, and reproduction in any

medium, provided the original author and source are credited.

Source of Support: Nil, Conflict of Interest: None declared. 